\title{
Assessment of diabetes empowerment amongst patients from India
}

\author{
K.V.S. Hari Kumar, Sandeep Kumar, Renjith Anish S, Shashank Pillarisetti \\ Department of Endocrinology, Command Hospital, Chandimandir, Haryana, India
}

\section{A B S T R A C T}

Background: Awareness about the disease is essential for all patients of diabetes to be part of patient centred approach. Patient empowerment is the central theme behind this new approach. We conducted this study to assess the psychosocial aspects and patient empowerment amongst patients with diabetes. Materials and Methods:We included 100 patients of diabetes (Type I and Type 2 only) with at least 2 years duration (age between 30-75 years, educated beyond graduation in any subject) in this cross-sectional observational study. The patients were divided into two groups: Group I (Age <60 yr) and Group 2 (Age $>60$ yr). Patient empowerment was assessed by Diabetes Empowerment Scale with three subscales reflecting the psychosocial aspects, readiness to change and the setting of diabetes goals. The data were analyzed with appropriate statistical tests using Graphpad Prism Software, version 6. Results:The study participants (42M and 58F) had a mean age of $56.5 \pm 13.7 \mathrm{yr}$, mean duration of the diabetes was $10.1 \pm 7.7 \mathrm{yr}$ and body weight of $67.2 \pm 1 \mathrm{I} .4 \mathrm{~kg}$. More number of elderly patients attended diabetes education programme, comfortable in posing a question about diabetes and were open to change with regard to their diabetes $(P<0.05)$. Correlation analyses revealed that the psychosocial aspects of diabetes improved with age and duration of diabetes $(<0.000 \mathrm{I})$. Conclusion: Old age and longer duration of diabetes are the major determinants for patient empowerment in diabetes. Patients have the potential to be empowered after more education and awareness about the disease.

Key words: Diabetes Mellitus, diabetes survey, patient's empowerment

\section{INTRODUCTION}

Diabetes encompasses a spectrum of diseases characterized by hyperglycemia as the principal metabolic abnormality. The disease is classically divided into type 1 diabetes mellitus (T1DM) characterized by insulin deficiency and type 2 diabetes mellitus (T2DM) due to insulin resistance. The requirement of exogenous insulin from the day of diagnosis is a distinctive factor of T1DM in comparison to T2DM. The need of daily insulin injection pose additional psychosocial burden in patients who are adjusting to the diagnosis of diabetes. India has the dubious distinction of

\begin{tabular}{|l|l|}
\hline \multicolumn{2}{|c|}{ Access this article online } \\
\hline Quick Response Code: & Website: \\
\hline & www.joshd.net \\
\hline & \\
\hline & \\
\hline
\end{tabular}

being the diabetes capital of the world with a population prevalence of around $10-15 \% .{ }^{[1]}$ Management of the diabetes and associated complications pose great challenges to the health care workers. The developed countries have a dismal record of the percentage of patients achieving the targets with respect to metabolic goals in diabetes. ${ }^{[2]}$ The situation is far worse in developing countries like India which is burdened with patient overload, lack of awareness amongst patients and doctors and also resistance to change also known as physician inertia. ${ }^{[3]}$

Management of diabetes is a complex model and involves a lot of stakeholders other than the physicians and patients. ${ }^{[4]}$ The ideal approach to any chronic disease is a long term, personalized, self care management approach along with appropriate guidance from the qualified doctors. ${ }^{[5]}$ Patients play an important role in the therapeutic decision making process and are involved in devising individual goals. This change in the approach to diabetes from physician centric to patient centric management is highlighted in the latest guidelines from the learned societies last

Corresponding Author: Dr. K.V.S. Hari Kumar, Department of Endocrinology, Command Hospital, Chandimandir - 134 107, Haryana, India. E-mail : hariendo@rediffmail.com 
year. ${ }^{[6]}$ Involvement of the patients in decision making requires a certain level of understanding about the disease and its complications. Decision making is an important prerequisite for patient empowerment and the components like health literacy, knowledge enhancement and personal skills enable the individuals for better problem solving capabilities. ${ }^{[7]}$ Unfortunately, there are a limited number of studies exploring the psychosocial aspects of diabetes from our country. ${ }^{[8,9]}$ Hence, we conducted this study to assess the psychosocial aspects and patient empowerment amongst diabetes patients.

\section{MATERIALS ANd Methods}

This cross sectional study was conducted at a tertiary level referral center in India. All patients with a diagnosis of diabetes (Type 1 and Type 2 only) for at least 2 years duration (age between 30-75 years, used oral hypoglycemic agents or insulin for more than 1 year, educated beyond graduation in any subject) were included in this cross sectional, observational study. The exclusion criteria were patients with secondary diabetes, gestational diabetes and the presence of any major illness, surgery or diabetic ketoacidosis in last 6 months or post-transplant diabetes. The patients were divided into two groups serially based on the age of the patient: Group 1 (Age $<60 \mathrm{yr}$ ) and Group 2 (Age $>60 \mathrm{yr}$ ). Previous studies suggest that young individuals had immature decision making capability and require more experience prior to empowerment. ${ }^{[10,11]}$ Hence we divided the patients into two groups based on their age. All patients were explained about the aims and objectives of the study prior to handing over the questionnaire. The local ethics committee at Command Hospital approved the trial protocol and all patients provided written informed consent.

All the participants were given a questionnaire to answer and the responses were evaluated. The questionnaire is developed by the University of Michigan Diabetes Training and Research Centre and is also known as Diabetes Empowerment Scale (DES-28). ${ }^{[12]}$ The first section of the questionnaire deals with the demographic information and the second section consists of a series of questions with five response categories ranging from 1 (strongly disagree) to 5 (strongly agree). The minimum and maximum value of the scale is 28 and 140, respectively, and the scale is subdivided into 3 scales based on a particular group of questions. The subscales explore three areas, i.e. managing psychosocial aspects of diabetes (score from 9 preselected questions), assessing the dissatisfaction and readiness to change (9 questions) and finally about setting the individual goals in the management of diabetes (10 questions). The validity and reliability of the scale were evaluated earlier in multiple studies and also correlated with glycemic control. ${ }^{[13,14]}$

Data are presented as mean $\pm \mathrm{SD}$ and a comparison between the groups was done using non-parametric (Mann-Whitney U test) and Chi-Square tests. Spearman's correlation test was used for correlation between numerical variables and a $P$-value of less than 0.05 was considered significant. The statistical analysis and graph generation was done using the Graph Pad Prism Software, Version 5 (Graph Pad Software, San Deigo, CA, USA).

\section{RESULTS}

The study participants consist of 42 males and 58 females with a mean age of $56.5 \pm 13.7 \mathrm{yr}$, mean duration of the diabetes was $10.1 \pm 7.7 \mathrm{yr}$ and body weight of $67.2 \pm 11.4 \mathrm{~kg}$. Type 1 Diabetes was seen in 17 participants and the remaining had T2DM. The comparison between the groups regarding the clinical profile and psychosocial assessment is given in Table 1. More number of elderly patients attended a diabetes education program, comfortable in posing a question about diabetes and were open to change with regard to their diabetes. Correlation analyses revealed

\begin{tabular}{|c|c|c|c|c|}
\hline Feature & Units & $\begin{array}{c}\text { Group } 1(\text { Age }<60) \\
n=51\end{array}$ & $\begin{array}{c}\text { Group } 2 \\
(\text { Age }>60) n=49\end{array}$ & $P$-value \\
\hline Age & Years & $46.3(11.4)$ & $67.4(5.7)$ & $<0.0001$ \\
\hline DM duration & Years & $7.6(6.3)$ & $13.4(8.1)$ & $<0.0001$ \\
\hline Type of Diabetes & $\mathrm{T} 1 / \mathrm{T} 2$ & $6 / 45$ & $10 / 39$ & 0.2043 \\
\hline Sex & $M / F$ & $17 / 34$ & $25 / 24$ & 0.3211 \\
\hline Q.5 - Diabetes preventing the daily routine & Score & $2.6(2.2)$ & $2.8(2)$ & 0.5504 \\
\hline Q6 - Ever attended a diabetes education programme & Yes/No & $36 / 15$ & $43 / 6$ & 0.0115 \\
\hline Q7 - Rating about the understanding of diabetes & Score & $4.8(1.9)$ & $4.8(1.5)$ & 0.8911 \\
\hline Q.14 - Able to fit DM into life positively* & Score & $5.5(1.4)$ & $5.1(1.5)$ & 0.1570 \\
\hline Q.15 - Comfort level asking questions about $\mathrm{DM}^{*}$ & Score & $5.3(1.5)$ & $6.2(1.2)$ & 0.0023 \\
\hline I - Managing psychosocial aspects of DM & Score & $35.5(3.5)$ & $36.8(5.6)$ & 0.1903 \\
\hline II - Assessing dissatisfaction and readiness to change & Score & $30.6(6.3)$ & $33.8(6.1)$ & 0.0087 \\
\hline III - Setting and achieving DM goals & Score & $38.5(6.5)$ & $39.6(6)$ & 0.3553 \\
\hline
\end{tabular}

Mean (S.D); * Score ranges from 1-10 on a continuous scale 
that the psychosocial aspects of diabetes improved with age and duration of diabetes as shown in Table 2. The DES scale does not provide any other demographic and medical variable limiting us for any further correlation analyses.

We also analyzed the data according to the gender (male vs. female), diabetes duration $(<10 \mathrm{yr}$ vs. $>10 \mathrm{yr})$ and type of diabetes (T1DM vs. T2DM) [Table 3]. Males and females did not differ in the three subscales but male patients were able to adjust diabetes into life positively and are more comfortable with posing diabetes related questions. Similar findings were seen in Type $1 \mathrm{DM}$ patients when compared with T2DM and younger patients in comparison to older patients.

\section{DISCUSSION}

Our data showed that the diabetes empowerment score is better with increasing age and longer duration of disease. Our findings suggest that elderly patients attended the diabetes education program more frequently than the younger patients. This may lead to increase in morbidity due to lack of awareness. ${ }^{[15]}$ Older patients with long standing disease pose more questions about diabetes due to factors like familiarity with the disease and doctors. Previous studies have shown that self efficacy has a strong influence on the control of diabetes in Indian population. ${ }^{[16]}$ Diabetes control was also influenced by the family support, education and positive attitude about the disease. This has lead to the development of specific tools pertaining to Indian patients to assess the quality of life in diabetes. ${ }^{[17]}$

The purpose of diabetes empowerment assessment is to encourage the patients involvement in the decision making process and the same is emphasized in the recently released national guidelines on the subject. ${ }^{[18]}$ Psychosocial aspects of diabetes did not differ in both groups of our study. However, correlation analyses suggested a linear relation between the age and duration of diabetes as shown in Figure 1. The surprising finding of our survey is that elderly patients have less satisfaction about the disease and are more ready to change than the younger patients. Support from social networks, health care providers and prevalent sociocultural factors influence the control of diabetes. ${ }^{[19,20]}$ Previous studies have revealed lack of

\begin{tabular}{lcc}
\hline Table 2: Correlation analyses of scores with age of the patient and duration of diabetes & \\
\hline Individual question & Age & Duration of DM \\
\hline Q5 - Diabetes preventing the daily routine & $r=0.002813$ & $r=0.00459$ \\
& $P=0.6002$ & $P=0.5027$ \\
Q6 - Ever attended a diabetes education programme & $r=0.006034$ & $r=0.04231$ \\
& $P=0.4424$ & $P=0.0401$ \\
Q7 - Rating about the understanding of diabetes & $r=0.02938$ & $r=0.01825$ \\
& $P=0.0881$ & $P=0.1802$ \\
Q14 - Able to fit DM into life positively & $r=0.00048$ & $r=0.00787$ \\
Q15 - Comfort level asking questions about DM & $P=0.8286$ & $P=0.3770$ \\
& $r=0.0079$ & $r=0.000174$ \\
I- Managing psychosocial aspects of DM & $P=0.0015$ & $P=0.8962$ \\
II - Assessing dissatisfaction and readiness to change & $r=0.04852$ & $r=0.04025$ \\
& $P=0.0277$ & $P=0.0454$ \\
III - Setting and achieving DM goals & $r=0.00165$ & $r=0.00775$ \\
& $P=0.6877$ & $P=0.3836$ \\
\end{tabular}

\section{Table 3: Analysis of the results based on the type of diabetes}

\section{Feature}

\section{Age}

DM duration

Sex

Q.5 - Diabetes preventing the daily routine

Q6 - Ever attended a diabetes education programme

Q7 - Rating about the understanding of diabetes

Q14 - Able to fit DM into life positively*

Q.15 - Comfort level asking questions about DM*

I - Managing psychosocial aspects of DM

II - Assessing dissatisfaction and readiness to change

III - Setting and achieving DM goals

Mean (S.D); * Score ranges from 1-10 on a continuous scale

$\begin{array}{cccc}\text { Units } & \begin{array}{c}\text { Group 1 (T1DM) } \\ \boldsymbol{n}=\mathbf{1 6}\end{array} & \begin{array}{c}\text { Group 2 (T2DM) } \\ \boldsymbol{n}=\mathbf{8 4}\end{array} & \boldsymbol{P} \text { value } \\ \text { Years } & 38.4(8.2) & 57.9(12.7) & <0.0001 \\ \text { Years } & 8.6(5.6) & 10.4(8.1) & 0.3840 \\ \text { M/F } & 7 / 9 & 35 / 49 & 0.3874 \\ \text { Score } & 3.6(2.8) & 2.4(1.9) & 0.0352 \\ \text { Yes/No } & 11 / 5 & 68 / 16 & 0.2767 \\ \text { Score } & 4(2.1) & 4.9(1.6) & 0.0450 \\ \text { Score } & 6.1(1.5) & 5.2(1.4) & 0.0304 \\ \text { Score } & 6.8(0.4) & 5.6(1.4) & 0.0012 \\ \text { Score } & 36.1(3.6) & 36.1(4.8) & 0.9503 \\ \text { Score } & 31.8(6.8) & 32.2(6.2) & 0.8036 \\ \text { Score } & 40.6(5) & 38.8(6.4) & 0.3008\end{array}$




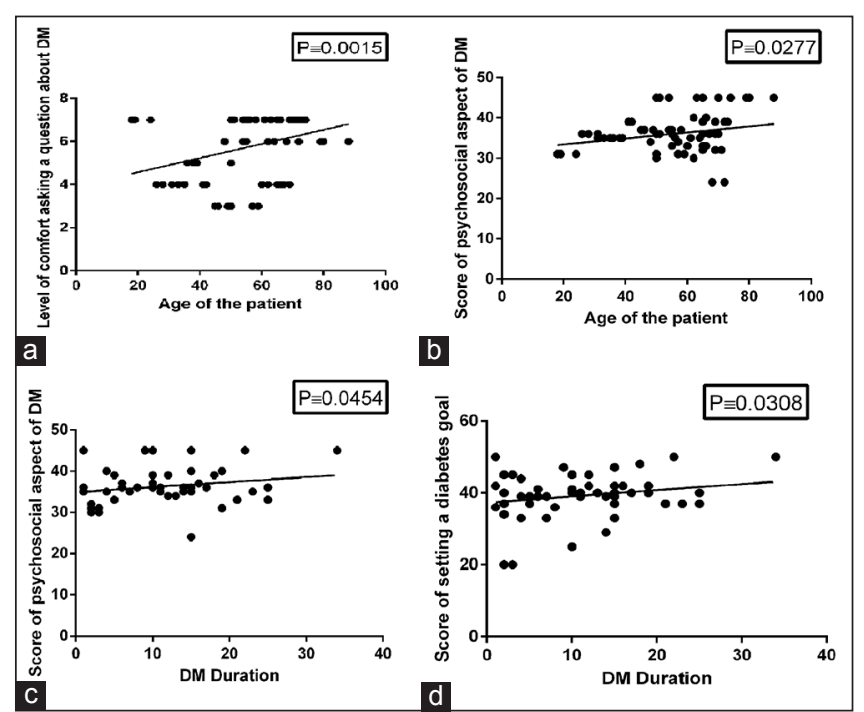

Figure 1: Correlation analyses of DES components with age of the patient $(a, b)$ and duration (c, d) of diabetes

diabetes knowledge even amongst patients with severe complications and there is a lack of policy initiative from government to improve the same. ${ }^{[21,22]}$

Understanding the belief and attitude of the patient is essential before recommending the therapeutic approach. Secondary analyses of our study showed that males have adopted the diabetes positively into their lifestyle, by virtue of the fact that India is a male dominated society. ${ }^{[23]}$ More number of T1DM patients have stated that they understand better about diabetes than T2DM patients. This is because of the increased awareness and education imparted to the T1DM patients. ${ }^{[24]}$ After the initial step of patient empowerment, it is the community empowerment which tackles the disease effectively. ${ }^{[25]}$

The limitations of our study are small sample size, lack of correlation with education level and the data being from a single center may not be representative of the population. To conclude, elderly patients with longstanding diabetes fare better in few psychosocial aspects and diabetes empowerment. Further studies, involving more number of patients are required for identifying the tools to empower patients in the management of diabetes.

\section{REFERENCES}

1. Joshi SR, Parikh RM. India-diabetes capital of the world: Now heading towards hypertension. J Assoc Physicians India 2007;55:323-4.

2. Joshi A, Mohan K, Grin G, Perin DM. Burden of healthcare utilization and out-of-pocket costs among individuals with NCDs in an Indian setting. J Community Health 2013;38:320-7.
3. Greenhalgh T. Barriers to concordance with antidiabetic drugscultural differences or human nature? BMJ 2005;330:1250.

4. Unger J, Hinnen D, Schreiner B, Parkin C. Putting medications where they belong: Practical advice for managing type 2 diabetes in clinical practice. J Am Assoc Nurse Pract 2013;25:65-76.

5. Russell AW, Baxter KA, Askew DA, Tsai J, Ware RS, Jackson CL. Model of care for the management of complex Type 2 diabetes managed in the community by primary care physicians with specialist support: An open controlled trial. Diabet Med 2013;30:1112-21.

6. Inzucchi SE, Bergenstal RM, Buse JB, Diamant M, Ferrannini E, Nauck $M$, et al. Management of hyperglycaemia in type 2 diabetes: A patient-centered approach. Position statement of the American Diabetes Association (ADA) and the European Association for the Study of Diabetes (EASD). Diabetologia 2012;55:1577-96.

7. Long AF, Gambling T. Enhancing health literacy and behavioural change within a tele-care education and support intervention for people with type 2 diabetes. Health Expect 2012;15:267-82.

8. Sivagnanam G, Namasivayam K, Rajasekaran M, Thirumalaikolundu subramanian $P$, Ravindranath $C$. A comparative study of the knowledge, beliefs, and practices of diabetic patients cared for at a teaching hospital (free service) and those cared for by private practitioners (paid service). Ann N Y Acad Sci 2002;958:416-9.

9. Kumar D, Bajaj S, Mehrotra R. Knowledge, attitude and practice of complementary and alternative medicines for diabetes. Public Health 2006;120:705-11.

10. Viklund G, Wikblad K. Teenagers' perceptions of factors affecting decision-making competence in the management of type 1 diabetes. J Clin Nurs 2009;18:3262-70.

11. Ramsay Wan C, Vo L, Barnes CS. Conceptualizations of patient empowerment among individuals seeking treatment for diabetes mellitus in an urban, public-sector clinic. Patient Educ Couns 2012;87:402-4.

12. Anderson RM, Funnell MM, Fitzgerald JT, Marrero DG. The Diabetes Empowerment Scale: a measure of psychosocial selfefficacy. Diabetes Care 2000;23:739-43.

13. Tol A, Shojaeezadeh D, Sharifirad G, Alhani F, Tehrani MM. Determination of empowerment score in type 2 diabetes patients and its related factors. J Pak Med Assoc 2012;62:16-20.

14. Eigenmann CA, Colagiuri R, Skinner TC, Trevena L. Are current psychometric tools suitable for measuring outcomes of diabetes education? Diabet Med 2009;26:425-36.

15. Ramachandran A, Snehalatha C, Ma RC. Diabetes in South-East Asia: An update for 2013 for the IDF Diabetes Atlas. Diabetes Res Clin Pract 2013 Nov 30.

16. Venkataraman K, Kannan AT, Kalra OP, Gambhir JK, Sharma AK, Sundaram KR, et al. Diabetes self-efficacy strongly influences actual control of diabetes in patients attending a tertiary hospital in India. J Community Health 2012;37:653-62.

17. Nagpal J, Kumar A, Kakar S, Bhartia A. The development of 'Quality of Life Instrument for Indian Diabetes patients (QOLID): A validation and reliability study in middle and higher income groups. J Assoc Physicians India 2010;58:295-304.

18. Kalra S, Sridhar GR, Balhara YP, Sahay RK, Bantwal G, Baruah MP, et al. National recommendations: Psychosocial management of diabetes in India. Indian J Endocrinol Metab 2013;17:376-95.

19. Venkatesh S, Weatherspoon L. Social and health care provider support in diabetes self-management. Am J Health Behav 2013;37:112-21.

20. Osman A, Curzio J. South Asian cultural concepts in diabetes. Nurs Times 2012;108:30-2. 
21. Sircar AR, Sircar S, Sircar J, Misra S. Patients' concepts and attitudes about diabetes. J Diabetes Complications 2010;24:398-403.

22. Lau SL, Debarm R, Thomas N, Asha HS, Vasan KS, Alex RG, et al. Healthcare planning in north-east India: A survey on diabetes awareness, risk factors and health attitudes in a rural community. J Assoc Physicians India 2009;57:305-9.

23. Ahmad N. Weak laws against acid attacks on women: An Indian perspective. Med Leg J 2012;80:110-20.

24. Snow R, Humphrey C, Sandall J. What happens when patients know more than their doctors? Experiences of health interactions after diabetes patient education: A qualitative patient-led study. BMJ Open 2013;3:e003583.

25. Shah SN. Preventing diabetes through community empowerment. J Assoc Physicians India 2008;56:493-4.

How to cite this article: Kumar KH, Kumar S, Anish SR, Pillarisetti S. Assessment of diabetes empowerment amongst patients from India. J Soc Health Diabetes 2014;2:77-81.

Source of Support: Nil. Conflict of Interest: None declared. 